\title{
Construction of an Integrated Positive Youth Development Conceptual Framework for the Prevention of the Use of Psychotropic Drugs among Adolescents
}

\author{
Tak Yan Lee \\ Department of Applied Social Studies, City University of Hong Kong, Hong Kong \\ Received 1 November 2010; Revised 10 August 2011; Accepted 21 August 2011 \\ Academic Editor: Joav Merrick
}

\begin{abstract}
This is a theoretical paper with an aim to construct an integrated conceptual framework for the prevention of adolescents' use and abuse of psychotropic drugs. This paper first reports the subjective reasons for adolescents' drug use and abuse in Hong Kong and reviews the theoretical underpinnings. Theories of drug use and abuse, including neurological, pharmacological, genetic predisposition, psychological, and sociological theories, were reviewed. It provides a critical re-examination of crucial factors that support the construction of a conceptual framework for primary prevention of adolescents' drug use and abuse building on, with minor revision, the model of victimization and substance abuse among women presented by Logan et al. This revised model provides a comprehensive and coherent framework synthesized from theories of drug abuse. This paper then provides empirical support for integrating a positive youth development perspective in the revised model. It further explains how the 15 empirically sound constructs identified by Catalano et al. and used in a positive youth development program, the Project P.A.T.H.S., relate generally to the components of the revised model to formulate an integrated positive youth development conceptual framework for primary prevention of adolescent drug use. Theoretical and practical implications as well as limitations and recommendations are discussed.
\end{abstract}

KEYWORDS: Chinese adolescents, drug abuse, developmental issue, positive youth development, primary prevention 


\section{REASONS FOR PSYCHOTROPIC DRUG ABUSE AMONG YOUNG PEOPLE IN HONG KONG}

According to the Narcotics Division of the Security Bureau of the Government of Hong Kong [1], the main reasons for drug use of the reported drug abusers aged under 21 in Hong Kong in 2009 were peer influence/to identify with peers $(66.7 \%)$, relief of boredom/depression/anxiety $(51.1 \%)$, curiosity $(43.0 \%)$, seeking euphoria or sensory satisfaction (33.6\%), and avoid discomfort of its absence (15.2\%). The percentages among different causes are not much different from that of similar surveys conducted in the last ten years. Besides, oversea research reported similar results [2]. However, these self-reported reasons are only overt reasons that youths themselves can realize. The underlying reasons for drug abuse are much more complex. For example, although some young people mentioned that they abused drug because they wanted to relieve their depression, the data does not show what made them depressed. With these overt reasons in mind, a critical examination of the theoretical underpinnings of adolescents' use and abuse of psychotropic drugs is presented in the next section.

\section{THEORIES OF DRUG USE AND ABUSE}

There are biological, psychological, as well as sociological theories of drug use. Although theories from these disciplines might seem competitive or even conflicting, an examination emphasizing their complementary nature is crucial. Each theory provides a partial explanation for drug use and has important prevention, treatment, and policy implications. Indeed, a comprehensive explanation could involve a combination of factors. For example, although we know that certain types of adolescent drug abuse are concentrated in areas of relative social and economic deprivation, most adolescents in similar situations do not abuse drugs.

\subsection{The Neurological Perspective}

From the neurological perspective, the immature brain of adolescents can explain why they show risky behaviors. The part of the brain (prefrontal cortex) which deals with the ability to make sound judgments and calm unruly emotions develops slowly. As a result, when determining risk versus reward, the immature adolescent brain tends to emphasize benefits while discounting dangers [3]. Different labels are given to this and related cognitive constraints, including damaged decision making ability or weak analytical ability, psychological barriers, or weak emotional control and expression. Neuroscientists found that the orbitofrontal cortex and anterior cingulated cortex activate in addicts while they are craving, intoxicated, and bingeing. When an addict goes through treatment to withdraw his or her addiction, these areas deactivate. This system accounts for the addict's overvaluing his or her favored drug and the total failure of any inhibition in seeking it out because prefrontal areas provide the overly positive appraisal of the drug and disable the neuronal arrays for inhibition of impulse [4]. Research also reveals that the adolescent brain is more responsive to drugs and thus more vulnerable to drug abuse than the adult brain, and it drives an interest in novelty that vastly exceeds that of children and adults [5]. In short, the immaturity of the adolescent brain can explain their risky behavior, weak will power, and relapse of drug addiction.

\subsection{The Pharmacological Perspective}

As a major theory under the biological perspective, arousal theory describes the adolescent drug user as a person whose body is malfunctioning with regard to the production of crucial neurotransmitters, making drug use self-medicating or as a way of coping [6]. As a result of the interaction between the pharmacological properties and the feeling experienced, the adolescent drug user's central nervous system habituates to the drug due to a neurotransmitter malfunction, and is then reinforced for engaging in the drug. Biological vulnerabilities may manifest in any of a number of physical and mental health problems. The typical cyclical 
processes may go like this: a stress producing mental health problem diminishes appropriate responses to stress, which increases stress levels, resulting in a more severe mental health problem; increased stress contributes to biological vulnerabilities and drug abuse, which then can affect physical and mental health [7].

\subsection{Genetic Predisposition}

According to the National Institute on Drug Abuse (NIDA), research evidence reveals that an individual's genetic makeup is one of the major factors in vulnerability to drug abuse [8]. While drug abuse is the result of a complex interplay of biochemical, psychological, social and environmental factors, genetic variance plays an important role in the susceptibility of adolescents' drug use and abuse. It is also claimed that the more severe the abuse, the greater the role of genetic factors $[9,10]$. While social, and environmental factors may determine whether an adolescent is exposed to drugs, genetics may help to explain why only some of those adolescents who are exposed use and abuse drugs.

To summarize, biological theories of drug use and abuse, including genetics, neurological, and pharmacological perspectives, provide explanations in terms of trauma and coping factors. These factors are almost identical to the model of factors contributing to victimization and substance abuse among women presented by Logan et al. [7, 11] after an extensive review of the literature. Specifically, these factors include genetic and biological vulnerabilities, drug use as a coping mechanism, as well as physical and mental health problems. In the original model [11], the last factor is named "child and adolescent victimization." These factors are shown in a revised model which is adopted with some revisions (like the name of the drug-dependent factor) and presented in Figure 1.

\subsection{Psychological Theories}

The focus of psychology is on the individual and is divided into clinical and behavioral disciplines. Psychological theories of drug abuse can be fundamentally categorized into two orientations-Freudian or psychoanalytic strain and behaviorism or learning theory. They provide some answers as to why adolescents who are exposed to the same physical and social environment react differently to the use and abuse of drugs [12]. Freudian theory postulates that human behaviors are largely driven through subconscious processes. Drug abuse is seen as a manifestation of unresolved developmental issues originated from oral, anal, or genital stages. While going through these stages, the person develops an id, ego, and superego. Deficiencies in the development are connected to adolescents' drug use and abuse. Drug abuse in adolescence is explained as an immature response to the stress typical of this period: the adolescent drug abuser gets around the demands of maturity. Although users reach chronological adolescence, they remain psychologically preadolescent because of weak emotional control and expression. The adolescent has not had sufficient experience in dealing with feelings of psychosocial stress in a mature manner, and psychotropic drugs are seen as a form of self-mediation [13]. Drugs let the adolescent avoid dealing with stress and frustration. As a result, the adolescent's ego function remains at an infantile level. Without much force driving for a change, his or her capacity for tolerance of stress and frustration remains primitive. Behaviorism builds its foundations in the laboratory of experimental psychology and is based on learning theory. All forms of behavior are conditioned, the results of learned responses to certain stimuli. Behavior is strengthened by its consequences and can be modified by operant conditioning: positive and negative reinforcement. Drugs can be used as powerful reinforcers, while withdrawal symptoms provide negative reinforcement. However, some adolescents manage to quit using drugs even after obtaining pleasurable experience. Those keep on using are more likely to be from an impoverished environment [14]. This leads to a sociological perspective.

The model presented by Logan et al. $[7,11]$ covers two categories of factors, that is, contextual and lifestyle factors. Although there are minor differences in terms of the specific content in the two versions, these two factors are in general closely related to psychological theories of drug use and abuse, which offer explanations including cognitive constraints, impaired decision making abilities, peer relationship 


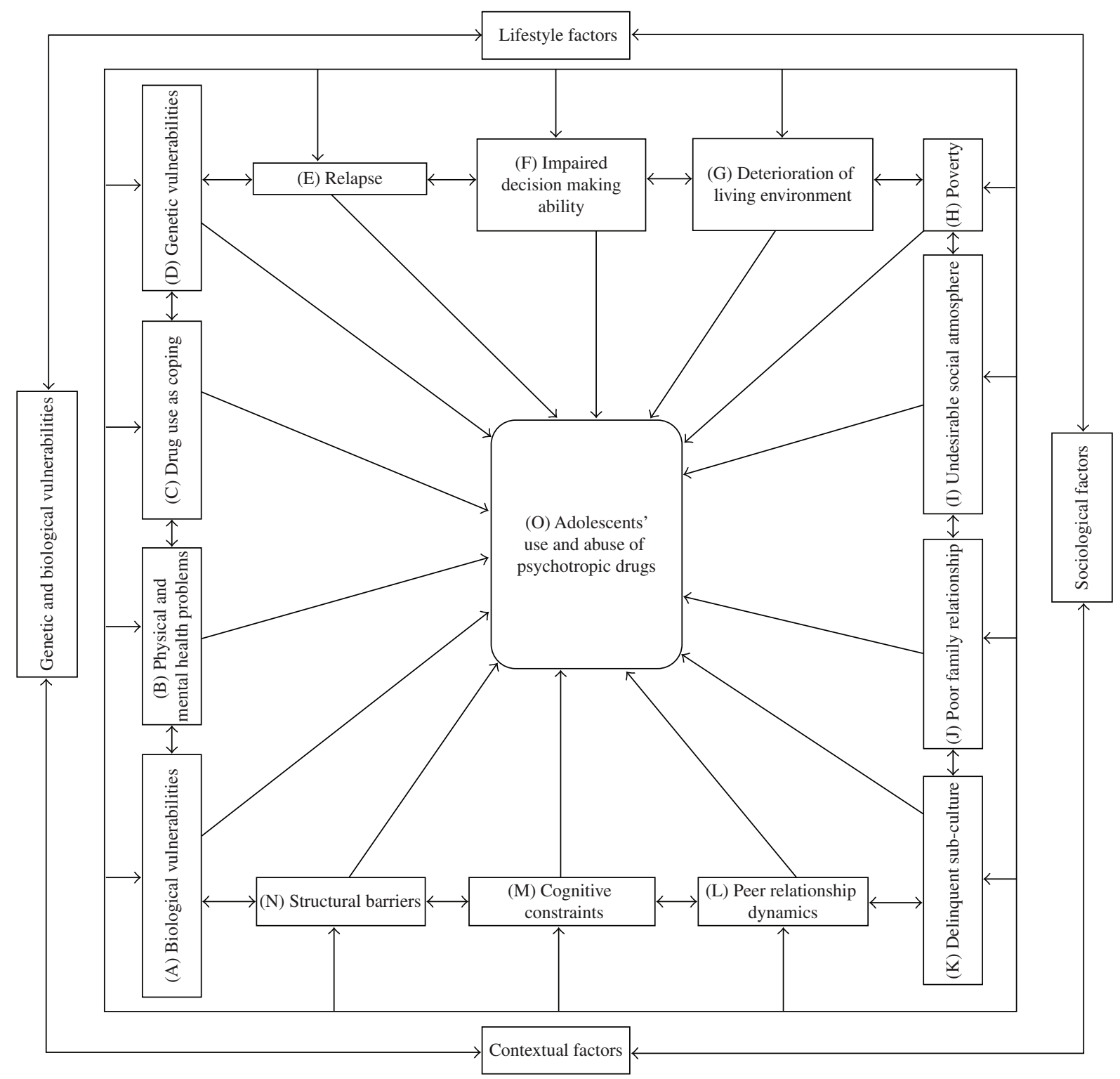

FIGURE 1: A revised model of factors contributing to adolescents' use and abuse of psychotropic drugs.

dynamics, and relapse. These specific factors are shown in the revised model of factors contributing to adolescents' use and abuse of psychotropic drugs presented in Figure 1.

\subsection{Sociological Theories}

Sociological theory is concerned with social structures and social behavior. It examines adolescents' drug use and abuse in its social context. A sociological perspective often views drug use and abuse as the product of social conditions and relationships that cause despair, frustration, hopelessness, and general feelings of alienation in the most socially disadvantaged. Sociological theories, including anomie (a strong sense of strain among the socially disadvantaged causing the individual abandoning all attempts to reach conventional social goals), differential association (the existence of excessive deviant associations with drug abusers over nondeviant or prosocial associations), social control theory (the individual's weak 
bond to society), subcultures and cultural deviance (subcultures not conducive to conventional types of achievement), and symbolic interactionism (societal reaction stigmatizing drug users thus causing a damaged self-image, deviant identity, and a host of negative social expectations), all provide plausible explanations. Many sociological studies have found that drug use among adolescents is motivated by intermittent feelings of boredom and depression and that, like other aspects of adolescence, drug use may be abandoned when the person reaches adulthood. Furthermore, contrary to conventional wisdom, research has found that drug use is typically a group activity of socially well-integrated youngsters [15]. That is, different from some psychological views, some adolescent drug users are socially competent.

To summarize, sociological theories of adolescents' drug use and abuse provide explanations as sociological factors (including poverty, undesirable social atmosphere, poor family relationship, and delinquent subculture), lifestyle factors (deterioration of living environment), and contextual factors (including peer relationship dynamics and structural barriers such as the availability of drugs, unavailability and/or unwillingness in seeking help, as well as poor social support network). These specific factors under the three domains are shown in the revised model presented in Figure 1.

The National Institute on Drug Abuse [16] outlines the lifestyle, contextual, sociological, as well as trauma and coping factors that are associated positively with adolescent substance abuse. The factors that are frequently found in deprived socioeconomic environments include:

(1) families whose members have a history of alcohol abuse and/or histories of antisocial behavior or criminality;

(2) inconsistent parental supervision, with reactions that swing from permissiveness to severity;

(3) parental approval or use of dangerous substances;

(4) friends who abuse drugs;

(5) children who fail in school during the late elementary years and show a lack of interest in school during early adolescence;

(6) children who are alienated and rebellious;

(7) children who exhibit antisocial behavior, particularly aggressive behavior, during early adolescence.

The above examination shows the complementary nature of different theories and demonstrates the need for a bio-psychosocial perspective, although the effect of the interaction of neurological and psychosocial factors is not yet clear. For example, the availability of choice of "novelty" for adolescents often depends on the social and economic situation as well as child-rearing practice of the family. This supports both psychological and sociological theories of drug use and abuse. From the psycho-sociological perspective, drug use depends on the actor who must learn that ingesting certain chemicals is desirable. Studies on subjective experience of drug abuse support that intoxication is not inherently pleasurable [17]. Expectations based on learning influence the direction of drug use. This shows the interrelatedness of both biological and psychological theories.

\subsection{Hypothesis}

The amount of ethically based testing that can be done by social and behavioral scientists is limited since we cannot subject human beings to high levels of stress, expose them to drugs, and then find out whether they become drug addicts. The social or behavioral sciences have to study the etiology of drug addiction in a more indirect manner. Therefore, Abadinsky's [12] hypothesis is commonly accepted: what promotes adolescents' drug use and abuse is a biologically and psychologically vulnerable adolescent- that is, having a tendency of neurotransmitter deficiency and an additive personality resulting from problematic family relationships, inappropriate reinforcement, the lack of healthy role models, contradictory parental expectations, and/or an absence of love and respect-living in deprived social circumstances who is exposed to certain psychoactive chemicals. 


\section{A REVISED MODEL OF FACTORS EXPLAINING ADOLESCENTS' USE AND ABUSE OF PSYCHOTROPIC DRUGS}

Over the years, scholars summarized a set of risk and protective factors for drug use [7, 11, 18-20]. It is difficult to categorize the factors because drug abuse results from the interplay between biological, psychological and sociological factors. According to system theory, to understand individuals' behavior, we have to understand the individuals, the environment around them, and the interactions between the individuals and the environment [12].

With the explanations provided by biologists, psychologists, and sociologists, the model of factors contributing to adolescents' use and abuse of psychotropic drugs developed by Logan et al. [7, 11] is adopted after minor revisions and presented in the next section.

In the revised model, there are three levels, that is, macro-, mezzo-, and microlevels.

\section{(1) The Macro Level (Dimensions)}

Four dimensions are included: Genetic and biological vulnerabilities, contextual factors, sociological factors, and life style factors. These four dimensions interplay and cover all risk factors of adolescent drug abuse.

\section{(2) The Mezzo Level (Factors)}

Under the board coverage of biological (factor (A), Figure 1) and genetic (factor (D), Figure 1) vulnerabilities, there are also two psychosocial factors, that is, factor (B), physical and mental health problems, and factor (C), drug use as a coping mechanism. Under contextual factors, there are three factors: peer relationship dynamics (factor $(\mathrm{L})$ ), cognitive constraints (factor $(\mathrm{M})$ ), and structural barriers (factor $(\mathrm{N})$ ). Poverty (factor $(\mathrm{H})$ ), undesirable social atmosphere (factor (I)), poor family relationship (factor (J)), and delinquent subculture (factor $(\mathrm{K})$ ) are grouped under sociological factors. Finally, impaired decision making ability (factor $(\mathrm{F})$ ), deterioration of living environment (factor $(\mathrm{G})$ ), and relapse (factor $(\mathrm{E})$ ) are treated as life style factors.

\section{(3) The Microlevel (Causes)}

At this level, perceived reasons provided by adolescent drug abusers and causes used in laymen terms are presented. These perceived reasons or alleged causes are easily understandable and are manifestations of the real causes. Under the dimension of genetic and biological vulnerabilities, there are two visible factors, that is, physical and mental health problems and drug use as coping. Within these two factors, there are five selfreported reasons, including curiosity and ostentation, boredom, low self-esteem, peer pressure, and weak problem-solving ability. Contextual factors, the second dimension, include three causes, that is, (1) complex situations associated with structural barriers (factor $(\mathrm{N})$, which means complicated situations confronted by the adolescent including the availability of drugs, unavailability and/or unwillingness in seeking help, present and/or past abusive relationship, and the lack of social support); (2) weak emotional control and expression associated with cognitive constraints (factor (M)); and (3) difficult interpersonal relationships generated from peer relationship dynamics (factor (L)). Sociological factors, the third dimension, covers four causes, that is, (1) obtaining quick money (e.g., through engaging in drug trafficking to relieve poverty, factor $(\mathrm{H})),(2)$ social exclusion (e.g., being isolated, bullied, or rejected) as a manifestation of undesirable social atmosphere (factor (I)), (3) alienated family relationship due to poor family relationship (factor (J)), and (4) the influence of delinquent peers as a result of differential association with delinquent subculture. The last dimension, life style factors, covers three causes, that is, (1) weak will power associated with relapse (factor (E)), (2) weak analytical ability as a result of impaired decision making ability (factor (F)), and (3) weak resilience associated with deterioration of living environment (factor $(G)$ ). The linkage between factors in the mezzo level and causes in the microlevel is shown in Figure 2. 


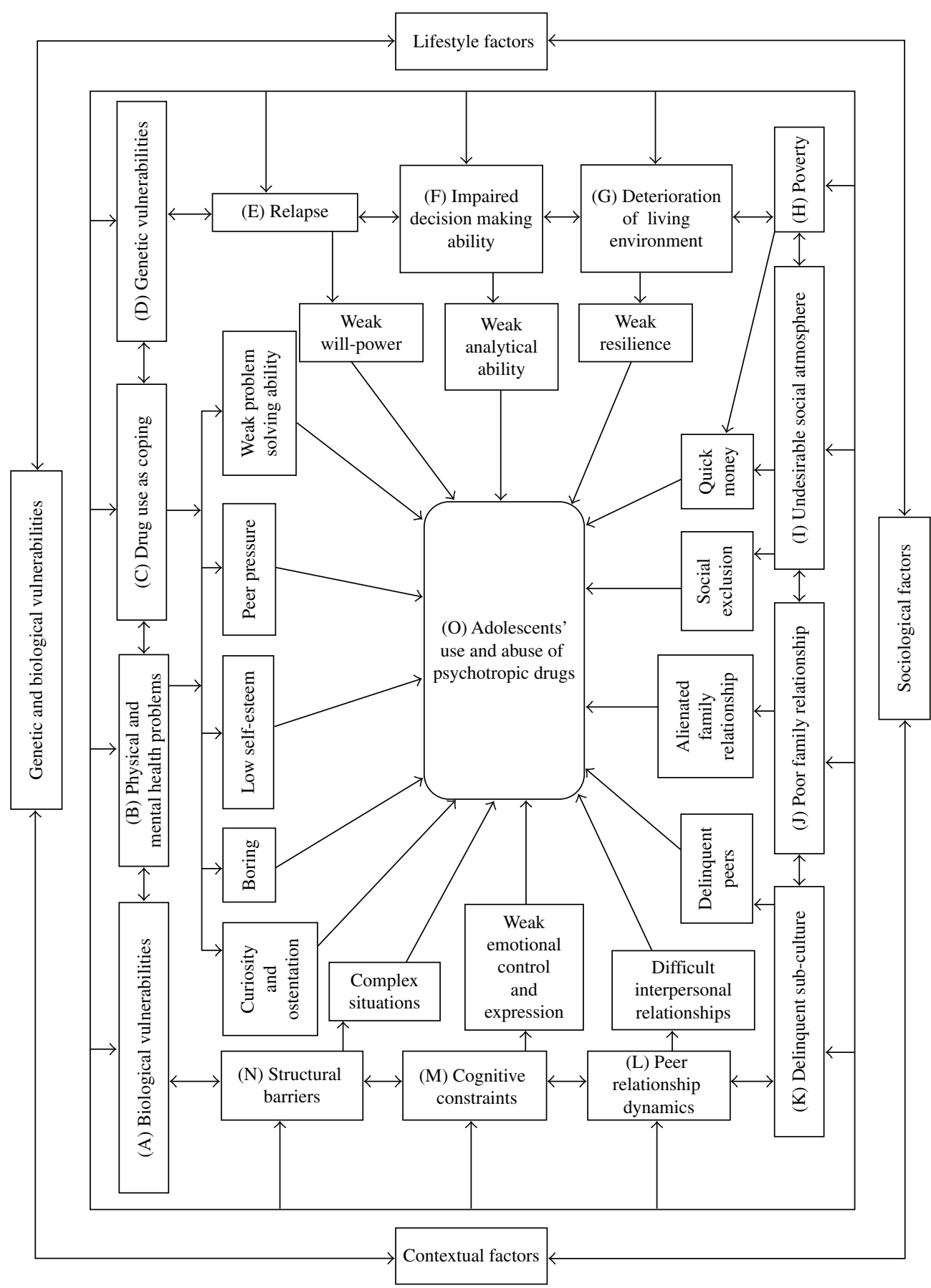

FIGURE 2: A revised model of causes of adolescents' use and abuse of psychotropic drugs at the microlevel.

\section{POSITIVE YOUTH DEVELOPMENT}

Based on their review of 77 programs on positive youth development, Catalano et al. [21] showed that 25 programs were successful and the following 15 positive youth development constructs were identified in the successful programs: (a) promotion of bonding (relationship with healthy adults and positive peers); (b) cultivation of resilience (enhanced capacity for adapting to change and stressful events in healthy and adaptive 
ways); (c) promotion of social competence (promotion of interpersonal skills and providing opportunities to practice such skills); (d) promotion of emotional competence (emotional maturity and management); (e) promotion of cognitive competence (development of cognitive skills and thinking); (f) promotion of behavioral competence (cultivation of verbal and nonverbal communication and taking action skills); (g) promotion of moral competence (development of a sense of right and wrong); (h) cultivation of self-determination (promoting sense of autonomy); (i) development of self-efficacy (promoting coping and mastery skills); (j) promotion of spirituality (development of purpose and meaning in life, hope, or beliefs in a higher power); (k) promotion of beliefs in the future (development of future potential goals, choices, or options); (l) development of clear and positive identity (promotion of healthy identity); (m) recognition for positive behavior (developing systems for rewarding); (n) providing opportunities for prosocial involvement (designing activities and events for program participants to make positive contribution to groups); (o) fostering prosocial norms (encouraging program participants to develop clear and explicit standards for prosocial engagement).

As we can see in Table 1, the 15 positive youth development constructs can be matched and applied in primary prevention program to mitigate the causes identified at the microlevel as shown in Figure 2. One additional component is added, that is, the promotion of money literacy [22]. This new component was developed to promote positive values and attitudes regarding the following aspects of money: strength, morality, exchangeability, caution, trouble, ownership, success and failure, as well as sense of achievement [23].

\subsection{Initial Empirical Evidence to Support the Construction of an Integrated Conceptual Framework: Evaluation Findings of the Project P.A.T.H.S.}

Based on the review of Catalano and his colleagues [21] and taking into consideration the adolescent developmental issues observed in Hong Kong, a 2-tier program, using the 15 positive youth development constructs, the Project P.A.T.H.S. (Positive Adolescent Training through Holistic Social Programs), was designed and implemented in Hong Kong since 2005 [24]. For the Tier 1 Program, it is a universal positive youth development program for students in Secondary 1 to Secondary 3 with the curricula developed by a research team comprising scholars from different disciplines (e.g., social work, psychology, and education). For the Tier 2 Program, it is a selective program targeting adolescents with greater psychosocial needs, developed by school social workers providing school social work service in the schools.

Shek [25] described objective outcome evaluation findings based on first six waves of data (i.e., Secondary 1 to Secondary 3 data) of the Project P.A.T.H.S. and revealed that based on different indicators students in the Experimental Group showed better development than did the Control Group students at Wave 6 after controlling the baseline differences. The findings also showed that students in the Experimental Group showed better growth trajectories than did students in the Control Group in terms of positive identity, behavioral competence, general positive youth developmental qualities, prosocial behavior, life satisfaction, and ability to control the use of the Internet. On the other hand, experimental subjects displayed less foul language and delinquency behavior than did the control participants. In the first six waves of the longitudinal data in Secondary 1 to Secondary 3 years, students in the experimental schools displayed a lower level of risk behavior (including substance abuse behavior) than did students in the control group in terms of abuse of ketamine, cannabis, pills and heroin (i.e., illegal psychotropic substances) as well as delinquent behavior. Obviously, the positive evaluation findings in the Project P.A.T.H.S. suggest that it is a promising program which can be used as an effective anti-drug education program in Hong Kong. Different evaluation studies consistently show that the Project P.A.T.H.S. can promote psychosocial competencies and reduce risk behavior (including substance abuse) in early adolescents in Hong Kong [25-35].

In view of the positive results, the research team chose five developmental problems, that is, drug education, sex education, antibully education, internet addiction prevention, as well as money literacy and started to develop a second version of the Tier 1 Program with the support from the funding body. The revised comprehensive and coherent conceptual framework presented in this paper linking existing theories of adolescents' drug use and abuse will be used for building curriculum units for the Project P.A.T.H.S. 
TABLE 1: Dealing with the causes of adolescents' use of psychotropic drugs through the promotion of 15 positive youth development constructs and money literacy.

\begin{tabular}{|c|c|c|c|}
\hline Code & $\begin{array}{l}\text { Positive youth } \\
\text { development constructs }\end{array}$ & Content & Responding to relevant causes \\
\hline $\mathrm{BO}$ & Bonding & $\begin{array}{l}\text { Promotion of relationship with } \\
\text { healthy adults and positive peers }\end{array}$ & $\begin{array}{l}\text { Alienated family relationship; } \\
\text { delinquent peers }\end{array}$ \\
\hline $\mathrm{RE}$ & Cultivation of resilience & $\begin{array}{l}\text { Enhancing capacity for adapting to } \\
\text { change and stressful events in } \\
\text { healthy and adaptive ways }\end{array}$ & Weak resilience \\
\hline $\mathrm{SC}$ & Social competence & $\begin{array}{l}\text { Promotion of interpersonal skills } \\
\text { and providing opportunities to } \\
\text { practice such skills }\end{array}$ & Difficult interpersonal relationships \\
\hline EC & Emotional competence & $\begin{array}{l}\text { Promotion of emotional maturity } \\
\text { and management }\end{array}$ & $\begin{array}{l}\text { Boredom; complex situations; weak } \\
\text { emotional control and expression }\end{array}$ \\
\hline $\mathrm{CC}$ & Cognitive competence & $\begin{array}{l}\text { Promotion of development of } \\
\text { cognitive skills and thinking }\end{array}$ & Weak analytical ability \\
\hline $\mathrm{BC}$ & Behavioral competence & $\begin{array}{l}\text { Cultivation of verbal and } \\
\text { nonverbal communication skills } \\
\text { and initiatives in taking action }\end{array}$ & $\begin{array}{l}\text { Weak will-power; weak problem } \\
\text { solving ability }\end{array}$ \\
\hline $\mathrm{MC}$ & Moral competence & $\begin{array}{l}\text { Development of a sense of right } \\
\text { and wrong }\end{array}$ & $\begin{array}{l}\text { Peer pressure; weak problem solving } \\
\text { ability }\end{array}$ \\
\hline$\overline{\mathrm{SD}}$ & Self-determination & Promoting sense of autonomy & Peer pressure \\
\hline SE & $\begin{array}{l}\text { Development of } \\
\text { self-efficacy }\end{array}$ & $\begin{array}{l}\text { Promotion of coping and mastery } \\
\text { skills }\end{array}$ & Peer pressure; low self-esteem \\
\hline SP & Spirituality & $\begin{array}{l}\text { Development of purpose and } \\
\text { meaning in life, hope, or beliefs in } \\
\text { a higher power }\end{array}$ & $\begin{array}{l}\text { Curiosity and ostentation; complex } \\
\text { situations }\end{array}$ \\
\hline $\mathrm{BF}$ & Beliefs in the future & $\begin{array}{l}\text { Development of future potential } \\
\text { goals, choices or options }\end{array}$ & $\begin{array}{l}\text { Low self-esteem; curiosity and } \\
\text { ostentation }\end{array}$ \\
\hline ID & $\begin{array}{l}\text { Development of clear } \\
\text { and positive identity }\end{array}$ & Promotion of healthy identity & Delinquent peers; low self-esteem \\
\hline PI & $\begin{array}{l}\text { Providing opportunities } \\
\text { for prosocial } \\
\text { involvement }\end{array}$ & $\begin{array}{l}\text { Designing activities and events for } \\
\text { program participants to make } \\
\text { positive contribution to groups }\end{array}$ & Low self-esteem; boredom \\
\hline $\mathrm{PN}$ & $\begin{array}{l}\text { Fostering prosocial } \\
\text { norms }\end{array}$ & $\begin{array}{l}\text { Encouraging program participants } \\
\text { to develop clear and explicit } \\
\text { standards for prosocial } \\
\text { engagement }\end{array}$ & $\begin{array}{l}\text { Alienated family relationship; quick } \\
\text { money; social exclusion }\end{array}$ \\
\hline \multirow[t]{2}{*}{ ML } & $\begin{array}{l}\text { Promoting money } \\
\text { literacy }\end{array}$ & $\begin{array}{l}\text { Promotion of positive values and } \\
\text { attitudes regarding the following } \\
\text { aspects of money: strength, moral, } \\
\text { exchangeability, caution, trouble, } \\
\text { ownership, success and failure, as } \\
\text { well as sense of achievement }\end{array}$ & Quick money; social exclusion \\
\hline & $\begin{array}{l}\text { Recognition for positive } \\
\text { behavior }\end{array}$ & $\begin{array}{l}\text { Developing systems for rewarding } \\
\text { positive behavior }\end{array}$ & $\begin{array}{l}\text { Since the last construct, recognition } \\
\text { for positive behavior, is relevant to } \\
\text { all other constructs, it is excluded }\end{array}$ \\
\hline
\end{tabular}


The following section describes how the 15 constructs plus the money literacy construct adopted in the Project P.A.T.H.S. relate generally to the components of the conceptual framework.

\section{AN INTEGRATED POSITIVE YOUTH DEVELOPMENT CONCEPTUAL FRAMEWORK FOR PRIMARY PREVENTION OF ADOLESCENT DRUG USE}

By further linking the 15 positive youth development constructs and the money literacy construct adopted in the Project P.A.T.H.S., an integrated positive youth development conceptual framework for primary prevention of adolescent drug abuse is developed (see Figure 3). It hypothesizes that drug use in adolescence is a result of the interaction between genetic and biological vulnerabilities with contextual, lifestyle, and sociological factors which will also further condition drug dependency.

According to this framework, an adolescent who is biologically and psychologically vulnerable (factors (A)-(D), (F), and (M), Figure 3) living in deprived social circumstances (factors (G)-(L), Figure 3) who is exposed to certain psychoactive chemicals (structural barriers, factor $(\mathrm{N})$ ) will promote adolescent drug use, continuous use, and subsequent abuse (relapse, factor (E)).

Theoretically, personal cognitions and perceptions are influenced by several factors (factors (E), $(\mathrm{F}),(\mathrm{K}),(\mathrm{L}),(\mathrm{M})$, Figure 1). According to social learning theory [36] drug abuse is a behavior that an adolescent is taught by his/her surroundings to adopt. This means that drug abuse is partly due to direct (e.g., friends' influence, ineffective parental control, parental attitudes, and availability) and indirect stimuli (e.g., delinquent peer models). Moreover, symbolic interaction [37] postulates that an adolescent's action is based on his/her interpretation of settings, symbols, and meanings. Factors (B), (C), (F)-(M) also find their grounds from the perspective of symbolic interaction. Furthermore, the operant conditioning theory explains why an adolescent tends to repeat drug taking behavior that is rewarded. These rewards can be of both a social and a biological nature, for example, the social acceptance gained when taking drug or the sensation of well-being when under drug's influence [38]. The value of taking drug, and the rationality in achieving this, is discussed in the theory of rational choice theory [39].

The links between the 15 positive youth development constructs and causes of the use of psychotropic drugs indicate how the constructs are used to tackle such causes as prevention measures. The lines denote linkages but by no means as the only connections. Significant linkages are shown diagrammatically in the elaborated conceptual framework presented in Figure 3.

\section{DISCUSSION}

This paper attempts to construct a conceptual framework of adolescent drug abuse by integrating existing theories and the positive youth development perspective. The framework specifies the plausible causes of adolescents' drug use and abuse. By incorporating the 15 positive youth development constructs which find growing empirical support in the project P.A.T.H.S., the integrated framework can be used in guiding preventive work. There are several unique features of the framework. First, it is based on the model developed by Logan et al. [7, 11] with minor revisions to fit the target of adolescents and accommodate adolescents' conception of the causes of drug use and abuse. Second, the revised model finds support from major psychological and sociological theories. Third, it echoes Abadinsky's [12] hypothesis that drug use in adolescence is a result of the interaction between genetic and biological vulnerabilities with contextual, lifestyle, and sociological factors which will also further condition drug dependency. Fourth, incorporating the 15 positive youth development constructs that find empirical support in the Tier 1 Program of the Project P.A.T.H.S. into the revised model [24-35], the integrated conceptual framework is a comprehensive and coherent one in responding to the different causes of adolescents' drug use and abuse.

The construction of the framework has two implications. First, it delineates mezzo and microlevels of factors and causes of adolescent drug abuse while accepting multiple causation and interactions among factors and causes. The second implication is on a practical level. It provides a solid foundation for guiding 


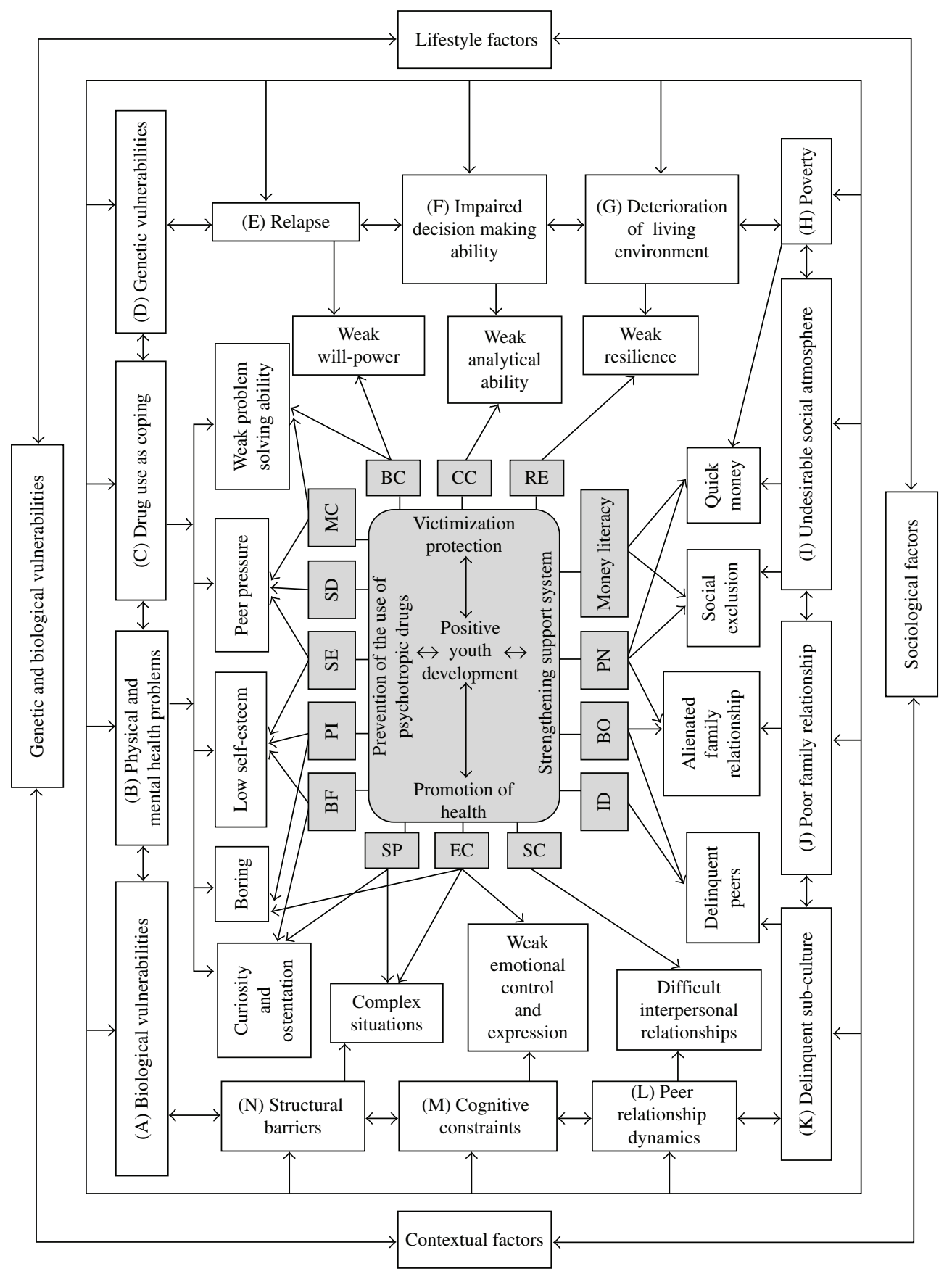

FIGURE 3: An integrated positive youth development conceptual framework for primary prevention of adolescent drug use.

the development, implementation and evaluation of program level primary intervention. While we have little control over the external environment (i.e., macro-level implication and dosage) in primary prevention, sound theoretical support is sought in developing the program [40]. The integrated conceptual framework adopting a positive youth development perspective can be applied in other social work or health science contexts, especially in educational and developmental issues of adolescence. It is particularly critical for classroom-based psychosocial primary intervention programs. 
There are several controversies with regard to the integrated conceptual framework. The first, an insignificant one, is that there are very often different opinions regarding how the factors and causes are categorized. Second, although the links between 15 positive youth development constructs and causes of the use of psychotropic drugs have been identified, they are only indicative and they are by no means absolute connections. While this ambiguity may be a weakness to a comprehensive primary prevention program, the advantage of having such an all-round development is that it increases the amount of relevant intervention to the target system (e.g., knowledge, values, beliefs, emotions, and behaviors) or the abilities of the adolescent. It should be noted that even though 20 new curriculum units of 35 minutes each will be designed with a view to strengthen the effect of drug prevention, all other units of the curriculum in the Tier 1 Program of the Project P.A.T.H.S. were designed to strengthen relevant abilities of the adolescent which would help participants resist drug use. All of the 120 curriculum units of the Tier 1 Program will contribute in dealing with different causes of psychotropic drug use in Hong Kong. Third, with regard to the all-inclusive manner in incorporating different theories, the integrated framework is considered not parsimonious. However, any perspective on adolescent drug abuse is bound to have limitations because it is just one way of examining the reality. Theoretically, the ability of psychological theories to explain is inhibited by environmental influences. The parable of the blind men and the elephant illustrates the importance of generating understanding and creating knowledge about the reality through interdisciplinary dialogue and debate. Although different theories of drug abuse may find limited support from their practical application and empirical testing, they are falsifiable in different psychological, social, cultural, legal and economic contexts. Intervention programs based only on single theories usually fail to handle properly the multiple, qualitatively different layers of context. By incorporating sociological, contextual, life style factors, elements of preventive intervention programs could target at all alleged and real causes for drug abuse. From the developmental and preventive perspective, the 15 positive youth development constructs may act like a master key to fit all locks. Capacity building including enhancement in values, knowledge and skills in one developmental issue may facilitate learning in another issue. Fourth, one of the major difficulties for the evaluation of a comprehensive program is that it is difficult to delineate which elements of the primary prevention program designed according to the framework would produce a more significant intervention effect. Systematically planned empirical studies are needed to resolve the issue. Finally, this framework does not particularly address the issue of gender. A theory that accounts for an isolated clinical phenomenon, that is, drug-taking behavior of male or female adolescents, does not have as wide-reaching an impact as one that considers the drug use of all adolescents. However, at the intervention level, gender-sensitive program designs are necessary. This helps the program designers and implementers avoid the risk of overgeneralization and gender-bias.

There are several limitations of this integrated conceptual framework. First, there may be initial bias in its construction because it relies only on limited empirical evidence from the project P.A.T.H.S. in preventing the problem of adolescents' drug use. Further effort in refining the framework is deemed necessary to avoid ongoing bias [41]. The framework has to be rigorously tested before it can be improved or falsified. Moreover, qualitative studies on how participants learn and apply what they have learned in the real life context are essential for refining the framework. Second, although the genetic factor is important, its interactive effects with biological, psychological and social factors, that is, living in deprived social circumstances and exposure to certain psychoactive chemicals, are yet to be established. At this stage, it is premature to establish a conclusive presumption of genetic control. The development of neuropsychological research has a long past but a short history, and many questions are not yet adequately answered. Therefore, Abadinsky's hypothesis [12] that a biologically and psychologically vulnerable adolescent living in deprived social circumstances who is exposed to certain psychoactive chemicals will promote drug use and abuse is valid and thus adopted. Finally, the two-dimensional figure cannot adequately handle some extra connections between a particular positive youth development construct and a certain cause, for example, the construct "development of clear and positive identity" (ID) can also tackle other relevant causes, including "low self-esteem" and "boring" as positive identity is associated with personal goals and achievement. Since the framework is used for guiding development of preventive programs, the link between the literature, the constructs, and the intended outcomes should be carefully delineated before program development. Further 
research on how each of the 15 positive youth development constructs and the construct of money literacy should be used to tackle different causes of drug use is recommended. Such studies will shed light on previously unexplored issues.

To conclude, the integrated framework can be used as the guiding theoretical framework to develop primary intervention at program level for the Project P.A.T.H.S. In the context of anti-drug education, the framework provides justifications that primary intervention developed under this framework will fulfill four functions: (1) prevention of the use of psychotropic drugs; (2) victimization protection; (3) strengthening support system; (4) promotion of bio-psychosocial aspects of health. It delineates the influences of psychosocial factors of adolescents' drug use and its risks. It also provides practical guidance for developing primary prevention practice of adolescents' use and abuse of psychotropic drugs.

\section{ACKNOWLEDGMENT}

The preparation for this paper and the Project P.A.T.H.S. were financially supported by The Hong Kong Jockey Club Charities Trust.

\section{REFERENCES}

[1] Narcotics Division, "Drug Statistics," 2010, http://www.nd.gov.hk/en/crda_ess.htm.

[2] L. D. Johnston and P. M. O'Malley, "Why do the nation's students use drugs and alcohol? Self-reported reasons from nine national surveys," Journal of Drug Issues, vol. 16, no. 1, pp. 29-66, 1986.

[3] V. F. Reyna and F. Farley, "Is the teen brain too rational?" Scientific American Mind, vol. 17, no. 6, pp. 58-65, 2006.

[4] R. Z. Goldstein and N. D. Volkow, "Drug addiction and its underlying neurobiological basis: neuroimaging evidence for the involvement of the frontal cortex," American Journal of Psychiatry, vol. 159, no. 10, pp. 1642$1652,2002$.

[5] L. Ellis, "Universal behavioral and demographic correlates of criminal behavior: toward common ground in the assessment of criminological theories," in Crime in Biological, Social, and Moral Contexts, L. Ellis and H. Hoffman, Eds., pp. 36-49, Praeger, Westport, Conn, USA, 1990.

[6] J. L. Whitten, "Behavioral response to novelty foreshadows neurological response to cocaine," NIDA Notes, vol. 21, no. 3, pp. 1-6, 2007.

[7] T. K. Logan, R. Walker, C. E. Jordan, and C. G. Leukefeld, Women and Victimization: Contributing Factors, Interventions, and Implications, American Psychological Association, Washington, DC, USA, 2006.

[8] N. D. Volkow, "NIDA Director's report to CPDD meeting: progress, priorities, and plans for the future," in Problems of Drug Dependence 2005, pp. 70-79, National Institute on Drug Abuse, Bethesda, Md, USA, 2006.

[9] D. E. Comings, "Genetic factors in drug abuse and dependence," in Individual Differences in the Biochemical Etiology of Drug Abuse, H. W. Gordon and M. D. Glantz, Eds., pp. 16-38, National Institute on Drug Abuse, Rockville, Md, USA, 1996.

[10] J. C. Crabbe, "Genetic contributions to addiction," Annual Review of Psychology, vol. 53, pp. 435-462, 2002.

[11] T. K. Logan, R. Walker, J. Cole, and C. G. Leukefeld, "Victimization and substance abuse among women: contributing factors, interventions, and implications," Review of General Psychology, vol. 6, no. 4, pp. 325-397, 2002.

[12] H. Abadinsky, Drug Use and Abuse: A Comprehensive Introduction, Wadsworth, Belmont, Calif, USA, 7th edition, 2011.

[13] O. G. Bukstein, D. A. Brent, and Y. Kaminer, "Comorbidity of substance abuse and other psychiatric disorders in adolescents," American Journal of Psychiatry, vol. 146, no. 9, pp. 1131-1141, 1989.

[14] T. J. Crowley, "The reinforcers for drug abuse: why people take drugs," in Classic Contributions in the Addictions, H. Shaffer and M. E. Burglass, Eds., pp. 367-381, Brunner, New York, NY, USA, 1981.

[15] B. Glassner and J. Loughlin, Drug Use in Adolescent Worlds: Burnouts to Straights, Macmillan, Houndmills, UK, 1987. 
[16] The National Institute on Drug Abuse, Drug Abuse and Drug Abuse Research, NIDA, Rockville, Md, USA, 1987.

[17] S. Peele, "Addiction to an experience: a social-psychological theory of addiction," in Theories of Drug Abuse: Selected Contemporary Perspectives, D. J. Lettieri, M. Sayers, and H. W. Pearson, Eds., pp. 142-144, National Institute on Drug Abuse, Rockville, Md, USA, 1981.

[18] R. H. Coombs and D. Ziedonis, Handbook on Drug Abuse Prevention: A Comprehensive Strategy to Prevent the Abuse of Alcohol and Other Drugs, Allyn and Bacon, Boston, Mass, USA, 1995.

[19] C. F. Levinthal, Drugs, Behavior, and Modern Society, Allyn and Bacon, Boston, Mass, USA, 6th edition, 2010.

[20] A. M. Pagliaro and L. A. Pagliaro, Substance Use among Children and Adolescents, John Wiley \& Sons, New York, NY, USA, 1996.

[21] R. F. Catalano, M. L. Berglund, J. A. M. Ryan, H. S. Lonczak, and J. D. Hawkins, "Positive Youth Development in the United States: Research Findings on Evaluation of Positive Youth Development Programs," 1998, http://aspe .hhs.gov/hsp/PositiveYouthDev99.

[22] T. Y. Lee, "Development of curriculum units on the developmental issue of money literacy in a positive youth development program: the project P.A.T.H.S. in Hong Kong," TheScientificWorldJournal. In press.

[23] C. K. Law, Money and Life: Survey Research Report, Federation of Youth Groups, Hong Kong, 1985.

[24] D. T. L. Shek, "Conceptual framework underlying the development of a positive youth development program in Hong Kong," in Positive Youth Development: Development of a Pioneering Program in a Chinese Society, D. T. L. Shek, H. K. Ma, and J. Merrick, Eds., pp. 81-92, Freund Publishing, London, UK, 2007.

[25] D. T. L. Shek, "Objective outcome evaluation of the project P.A.T.H.S. in Hong Kong: findings based on individual growth curve models," TheScientificWorldJournal, vol. 10, pp. 182-191, 2010.

[26] D. T. L. Shek, "Effectiveness of the Tier 1 Program of the Project P.A.T.H.S.: preliminary objective and subjective outcome evaluation findings," TheScientific WorldJournal, vol. 6, pp. 1466-1474, 2006.

[27] D. T. L. Shek, A. M. H. Siu, and T. Y. Lee, "The Chinese Positive Youth Development Scale: a validation study," Research on Social Work Practice, vol. 17, no. 3, pp. 380-391, 2007.

[28] D. T. L. Shek, Ed., "Special issue: evaluation of project P.A.T.H.S. in Hong Kong," TheScientificWorldJournal, vol. 8, pp. 1-94, 2008.

[29] D. T. L. Shek and R. C. F. Sun, "Evaluation of Project P.A.T.H.S. (Secondary 1 Program) by the program participants: findings based on the Full Implementation Phase," Adolescence, vol. 43, no. 172, pp. 807-822, 2008.

[30] D. T. L. Shek, A. M. H. Siu, Y. L. Tak, K. C. Chau, and R. Chung, "Effectiveness of the Tier 1 Program of Project P.A.T.H.S.: objective outcome evaluation based on a randomized group trial," TheScientificWorldJournal, vol. 8, pp. 4-12, 2008.

[31] D. T. L. Shek, "Effectiveness of the tier 1 program of project P.A.T.H.S.: findings based on the first 2 years of program implementation," TheScientificWorldJournal, vol. 9, pp. 539-547, 2009.

[32] D. T. L. Shek, "Using students' weekly diaries to evaluate positive youth development programs: the case of project P.A.T.H.S. in Hong Kong," Adolescence, vol. 44, no. 173, pp. 69-85, 2009.

[33] D. T. L. Shek and C. S. M. Ng, "Secondary 1 program of project P.A.T.H.S.: process evaluation based on the co-walker scheme," TheScientificWorldJournal, vol. 9, pp. 704-714, 2009.

[34] D. T. L. Shek and H. K. Ma, "Editorial: Evaluation of the project P.A.T.H.S. in Hong Kong: are the findings replicable across different populations?" TheScientificWorldJournal, vol. 10, pp. 178-181, 2010.

[35] D. T. L. Shek and R. C. F. Sun, "Effectiveness of the tier 1 program of project P.A.T.H.S.: findings based on three years of program implementation," TheScientificWorldJournal, vol. 10, pp. 1509-1519, 2010.

[36] A. Bandura, Social Learning Theory, Prentice Hall, Englewood Cliffs, NJ, USA, 1977.

[37] H. Blumer, Symbolic Interactionism: Perspective and Method, Prentice Hall, Englewood Cliffs, NJ, USA, 1969.

[38] B. F. Skinner, Science and Human Behavior, Free Press, New York, NY, USA, 1953.

[39] G. S. Becker and K. M. Murphy, "A theory of rational addiction," Journal of Political Economy, vol. 96, pp. 675-700, 1988.

[40] N. A. Polansky, "There is nothing so practical as a good theory," Child Welfare, vol. 65, no. 1, pp. 3-15, 1986.

[41] R. J. Vaughan and T. F. Buss, Communicating Social Science Research to Policymakers, Sage, Thousand Oaks, Calif, USA, 1998. 
This article should be cited as follows:

Tak Yan Lee, "Construction of an Integrated Positive Youth Development Conceptual Framework for the Prevention of the Use of Psychotropic Drugs among Adolescents," TheScientificWorldJOURNAL, vol. 11, pp. 2403-2417, 2011. 